\title{
Spinal Cord
}

National Cancer Institute

\section{Source}

National Cancer Institute. Spinal Cord. NCI Thesaurus. Code C12464.

The elong ated, approximately cylindrical part of the central nervous system of vertebrates that lies in the vertebral canal and from which the spinal nerves emerge. 